\title{
Research on the Education about Development of Cultural Tourism about Henan Province
}

\author{
Hexiang $L^{1}$ \\ ${ }^{1}$ Information Engineering Department, Zhengzhou University of Industrial Technology , Xinzheng, \\ 451100, China \\ a517564763@qq.com
}

Keywords: Henan; Cultural tourism; Development status; Advance countermeasure

\begin{abstract}
The cultural tourism industry is one of the most important industries in the current society. It can be said that it is one of the most potential industries in the 21 st century. Through tourism, People can use consumption to stimulate economic and social development and meet people's special spiritual needs. Henan is renowned at home and abroad cultural tourism province, in recent years, cultural tourism industry has made rapid development, and also become one of the important step to build a cultural Province, cultural tourism industry has made rapid development compared with the previous in Henan, but on the whole, the development of cultural tourism resources is still not enough, but it has a certain gap between the coastal more developed provinces. Henan province's GDP reach 401.060 billion yuan in 2016, it can be said that the current economic base of our province has been more strong, but the cultural tourism industry is still weak.so it must put the development of cultural tourism industry in a high level of strategic height, Fully realize its importance and urgency, In response to the central government's acquire to vigorously develop the cultural tourism industry, spare efforts to change the advantages of cultural tourism resources to industrial advantages, make it better to meet the people's growing spiritual and cultural consumption needs.
\end{abstract}

\section{Introduction}

At present, the tourism industry in China, although the tourism demands have show new characteristics, but the tourism industry is facing a new development issues, so it has to face the new trend of industrial integration, in this context, China's tourism Industry and cultural industry integration is coming. Henan Province has recognized the necessity and importance of the integration of the two industries. Therefore, exploring the integration of Henan tourism industry and cultural industry has a positive role in this context.

\section{The Development of Cultural Tourism Industry in Henan Province}

If you want to experience Chinese history and culture, you must go Henan, In Henan can feel five thousand years of Chinese civilization, tracing the roots of the Chinese nation. It is because Henan has so many advantages in resources, it makes Henan cultural tourism rapid and healthy development in recent years, from small to large, has formed a certain industrial system and industrial scale. The cultural tourism industry of our province started in the late 1980s and early 1990s, but did not form a great influence. Since 2000, the Provincial Party Committee and Provincial government deployed to carry out the "three points to a line" civilization area, create civilized city, based on Henan rich cultural tourism resources to Zheng, bian, Luo three cities as the focus, World cultural heritage (Long Men Shi $\mathrm{Ku}$ ), four national historical and cultural cities (Zheng, Pei, Luo, Shangqiu) and five provincial historical and cultural cities, as well as together with 52 national emphasis cultural relics protection Units to create a high quality cultural tourism route, directly stimulated the economic development. In 2000, Long men Grottoes of Luo yang successful apply for the world cultural heritage, forming a leading cultural tourism in our province. Then, All parts of the original integration of cultural relics, education, tourism and other different sectors of the cultural resources, through this built or renovated a large number of cultural 
attractions. Such as Luo Yang Long Men Grottoes, Kai Feng Qing Ming River Park, Deng Feng Song Yang College, Zheng Han ancient city, Zheng Wang tomb of Xin Zheng, Xi Zhou "driving six of emperor " carriage pit of Luo Yang, Maoguo museum of San Men Xia, government office of Nanyang, Nei Xiang and Ye Xian, they have become a strong support point for cultural tourism industry in our province. Long Men Grottoes of Luoyang and Shaolin Temple of Songshan, they have a huge influence in the world as the leading area of Henan. Qing Ming River Park of Kaifeng, Huang emperor hometown of Xinzheng and other scenic area are known at home and abroad because its unique historical and cultural background.

Henan is one of the main birthplaces of the Chinese nation, The dynasty replacement and the rise and fall of the nation, Through the long process of civilization accumulate rich cultural tourism resources. Whether there is a cultural heritage of the existence of cultural resources, or spread in the community of intangible cultural tourism resources are very rich, and many cultural tourism resources market prospects are very broad.

In the national cultural tourism industry development pattern and cultural tourism market system, Henan is in the "middle of middle", link the east and west, the south and north of the important strategic position, with the "central rise" strategy implementation, He nan may become the great important "Central Plains platform" in future of China's economic and cultural landscape.

\section{The Development of Cultural Tourism Industry Problems of Henan Province}

Tourism Product Content Mining is not Deep, the Level of Organization is not High. Henan tourism whether can achieve the advantages of transformation, in the fact, the innovation is key, that is how to deal with the external packaging of Henan culture and the depth of the excavation, how to make heavy history becomes no longer heavy, so that the ancient culture glow with new life. In the sustainable use of resources, cultural resources are the highest level and the most development value of resources. Henan Province, although the number of tourism products (viewpoint, scenic spots), but the depth of excavation is not enough, the expression of the information outside is relatively simple and the performance is almost similar. Henan cultural tourism scenic development and construction is inadequate, many attractions are "can listen but see", resource advantages have not yet transformed into product advantages. Such as the renovation of the Shaolin Temple gives the feeling is like a city park, Wushu culture is not enough. As Xu Guangchun said: "Henan historical figures, but Henan cultural tourism can not see the history of celebrities, Only see things but see people, lack of cultural attractions and story, the same as lack of attractiveness.

Cultural Tastes and Brand is not Enough. tourism culture taste is low in Henan Province tourism industry has been and not a good solution to the problem, the problem weaken the competitiveness of Henan tourism industry. The power of the brand is invisible and sustainable. Once the brand establish, it must benefit from infinity. Currently in some areas of Henan, we see is the low cultural taste of the attractions. The talk about the transformation of tourist attractions and construction, immediately thought to cover the temple of the Buddha made the palace to please gods, So many new tourist attractions in the performance approach on the same, low-level repeat; About the content arrangement, rough and custom, Greatly affected the image of Henantourism resources and its due value, It make negative effect frequently in the tourism industry, then losing the competitive ability

Tourism Industry Chain is Short, the Tourism Industry Structure is Unreasonable. Relative to foreign and tourism developed provinces, Henan tourism industry chain is short. The integrity of the tourism industry chain has not yet formed, the tourism industry in the national economy has not yet fully established the status. Therefore, there is a long way to go with the aim of the province of tourism. Food place travel play, the article is not enough. Features snack food area, special entertainment consumption and tourist souvenir digging depth is not enough. Henan is lack of sensitivity to the development of new tourism products, It can not meet the needs of market changes. Not only tourism products in Henan are difficult to enter the international market but also 
even overseas tourists in other parts of China can be purchased in Henan tourism products are also very limited.

Management System is not Perfect, Running Mechanism Rigid. As the tourism authorities set up later than other departments, the various functions of the points have been stereotypes at the beginning, resulting in the functions of tourism management has not been implemented, tourism management efficiency is low, The Henan cultural tourism resources belong to different departments of management, different departments constraints each other, so it is not a good docking with the market. several management system make the department only concerned about their own benefits, immediate benefits, Benefit rather than protection, It affects the sustainable development of cultural tourism in Henan. It is worth mentioning that the overall style of the city is also an important part of tourism, but most of the city only pay attention to the construction of the classic scenic area, not the construction of urban tourism environment atmosphere, making serious separation between the scenic spots and urban style, out of the city background contrast, There is no overall planning and the overall publicity, the combination between products and integrated marketing awareness of scenic spots is lack, the government's coordination function is not well play, This has become the weakest point in the overall development of the tourism industry.

\section{The Suggestions to Promote the Development of Cultural Tourism Industry in Henan Province}

Government provide good support policies. In the tourism industry and cultural industry integration development process, the government departments as an irreplaceable and coordinated role. First of all, in the early stages of tourism industry and cultural industry integration, the government plays the role of pioneer. Henan Province is located in the Central Plains, rich cultural heritage, the prospects of tourism and cultural integration is good. The province's tourism industry and cultural industry integration development has grown up through the government and the relevant departments. Such as LuoYang, Kaifeng, AnYang and other ancient deep culture, Shaolin Kung Fu of Songshan is well known at home and abroad, all over the world of Chinese returned to Henan to find roots and ancestors. And these cultural characteristics related to the tourist attractions have also been established. Such as the ancient city of Kaifeng Songdu Cultural Industry Park, Luoyang Tang ancient city of cultural industry park, YinXu cultural park as the representative of the AnYang business culture circle. Second, the government give financial support to the tourism industry and cultural industries. The government allocates funds to all enterprises through the national budget, sets up special funds and encourages projects that support the integration of new tourism culture. The government can also through investment for the tourism industry and cultural industries to give financial support.

Strengthen scientific and technological innovation, providing technical support. The high technology is popular in the 21 century, the integration of tourism industry and cultural industry can not be separated from the promotion of science and technology. First, the integration of the tourism industry and the cultural industry need science and technology. Such as the integration of advanced technology, "Zen Shaolin music ceremony" is performed by nearly a thousand Shaolin monks, that is rare in recent years. 180 degrees of panoramic view, the beautiful mountain springs, looming temple of the ancient temple, constitute the true background of the performance, the futuristic futon seat to become a major feature of the theater. The whole performance is entirely in the embrace of nature, the most advanced surround sound of the world and the sound of nature sound, wind, forest, insects and other together, constituting a kind of sounds of nature Zen rhyme. So bold and large-scale real performance profoundly shocked the audience's mind, Making people in the busy complex earth calm down to listen the true meaning of life and experience the baptism of the soul. The Qingming on the river garden of Kaifeng "big song east jing dream", the same use of the sound, light, electricity, water, fire, shadow, sound and other high-tech factors, It can be seen that the development of cultural tourism industry is a feasible way to develop tourism industry by using real science, animation tour, movie tour, music tour, art tasting and book appreciation. 
Cultivating talents who are fluent in foreign languages. The integration of Tourism industry and cultural industries can not be separated from the support of talent, talent is fundamental driving force to promote the tourism industry and cultural industry integration development. Compared with the traditional tourism professionals, the integration of tourism industry and cultural industry needs more higher talent, that is who with a certain level of culture and proficient in foreign language professional tourism talent, so it need to increase the training of tourism talents. At present, the province's emphasis on foreign language about tourism management is not enough. Although some universities set up the relevant tourism English subjects, but tourism is an interdisciplinary English, only in the tourism industry set up an English subject is not enough. Learn from the experience of colleges and universities at home and abroad, many tourism English is set up by the Foreign Language Institute, the tourism professional subjects are learning and explain in English, so for the tourism talents of the English level has been Guaranteed, and also enriched the tourism professional knowledge. In the study of theoretical knowledge combine with local tourism resources, at the same time strengthen the tourism sector, cultural departments and institutions of higher learning to provide students with practical opportunities to develop their practical ability. regulating the cultural tourism market to develop a reasonable talent support policies and encourage college graduates to choose the cultural and tourism sector employment.

\section{Conclusion}

On the basis of the research results of cultural tourism industry development at home and abroad, this paper gives the concept and connotation of cultural tourism and cultural tourism industry, Analyzing the present situation, existing problems and constraints of cultural tourism industry in Henan province, Further clarified the cultural tourism industry in Henan national economy and social development the important position. Through systematic research, it can be concluded that the following key factors must be firmly grasped in the process of promoting the development of cultural tourism industry in Henan: First, we must actively cultivate the cultural tourism market system. Second, we must persist to the principle of sustainable development. Third, we must make full use of domestic and foreign markets. Fourth, we must build a reasonable cultural tourism resources property rights system. Fifth, we must strengthen the cultural tourism industry management personnel training. The key to the sustainable development of cultural tourism industry is talent. To speed up the training of cultural tourism industry talent in our province, it need strengthen cooperation with domestic and foreign tourism institutions of higher learning, cultivating highly educated, high quality, strong application of cultural tourism talent, while cultural tourism enterprises and institutions should do a good job of internal training, Upgrade quality of personnel and international perspective and establish and improve the cultural tourism industry talent pool, improving the treatment of talent to meet the international requirements with international practice. At last, the development and expansion of the province's cultural tourism industry needs in the system, mechanism, funding, personnel training, marketing planning and other aspects of multi-ways, fully mobilize all aspects of the power, the effective use of domestic and international markets, Meeting The people's growing spiritual and cultural needs and promote the development of economic and social sciences

\section{References}

[1] Lin Ma. Research on the Development of Cultural and Creative Industry and Tourism Industry[D].KunMing: Finance and Economics School YunNan.

[2] Yan Shi. Research on the Interactive Development of Tourism Industry and Cultural Industry from the Perspective of Industrial Convergence[J]. Journal of Northeast University of Finance and Economics, 2012, 3(2)

[3] Yongheng Zhang. Zen Shaolin music ceremony if can ease the "aesthetic fatigue"[N]. People Daily Overseas.2010-08-20(11) 